What is already known on this topic

Patients with stroke returning home from hospital often encounter unanticipated disability and difficulties in adapting to the home environment

No intervention has been shown to alleviate these problems

\section{What this study adds}

A brief programme of domiciliary occupational therapy can enhance recovery and reduce the risk of deterioration in patients with stroke returning home

Rehabilitation should be extended beyond discharge from hospital

intervention has been observed previously and used to justify a more prolonged therapy input. ${ }^{45}$ Reducing the longer term impact of stroke remains a major challenge.

\section{Implications}

Our results lend support to the principle of extending routine stroke rehabilitation from the inpatient period to postdischarge period. Our resource analysis shows that the service costs are significant but that one therapist could manage 80-100 patients per year and prevent about 10 deteriorating in function after discharge home. We did not attempt to reduce hospital stay, but two recent British trials of early hospital discharge with a domiciliary multidisciplinary rehabilitation have shown a shortening of the period of inpatient care with no apparent adverse effect on patient outcomes. ${ }^{10} 11$ If confirmed, this potentially offers a way of improving postdischarge rehabilitation without incurring major additional service costs.

We thank the patients and carers who contributed to the study.

Contributors: LG planned and conducted the trial and drafted the final report. PL planned and supervised the trial; he will act as guarantor for the paper. AW provided health economic input and analysis. AA contributed to the design and conduct of the trial. GDM provided independent data analysis and statistical advice. All authors contributed to the redrafting and approval of the final report.

Funding: Chest Heart and Stroke Scotland provided the funding for this study. Additional support came from Glasgow Royal Infirmary NHS Trust and the chief scientists office, Scottish Office, which funded a research training fellowship for LG.

Competing interests: None declared.

Forster A, Young J. Stroke rehabilitation: can we do better? BMJ 1992:305:1446-7.

2 Corr S, Bayer A. Occupational therapy for stroke patients after hospital discharge. Clin Rehab 1995;9:291-6.

3 Gilbertson L. A randomised controlled trial of home based occupational therapy for stroke patients. MSc thesis. University of Glasgow, 1998.

Drummond AER, Walker MF. A randomised controlled trial of leisure rehabilitation. Clin Rehab 1995;9:283-90.

5 Logan PA, Gladman JRF, Lincoln NB. A randomised controlled trial of enhanced social service occupational therapy for stroke patients. Clin Rehab 1997;11:107-13.

6 Wade DT. Measurement in neurological rehabilitation. Oxford: Oxford University Press, 1992.

7 Dennis MS, O'Rourke S, Slattery J, Staniforth T, Warlow C. Evaluation of a stroke family care worker: results of a randomised controlled trial. BMJ 1997;314:1071-7.

8 Walker MF, Gladman JRF, Lincoln N, Siemonsma P, Whiteley T. Occupational therapy for stroke patients not admitted to hospital: a randomised controlled trial. Lancet 1999;354:278-80

9 Gladman J, Barer D, Langhorne P. Specialist rehabilitation after stroke. Effective in the short term, but more work needed in the long term. BMJ 1996;312:1623-4.

10 Rudd AG, Wolfe CDA, Filling K, Beech R. Randomised controlled trial to evaluate early discharge scheme for patients with stroke. BMJ 1997:315:1039-44.

11 Rodgers H, Soutter J, Kaiser W, Pearson P, Dobson R, Skilbeck C, et al. Early supported hospital discharge following acute stroke: pilot study results. Clin Rehab 1997;11:280-7.

(Accepted 13 December 1999)

\title{
Six year survey of screening for Down's syndrome by maternal age and mid-trimester ultrasound scans
}

\author{
David T Howe, Robert Gornall, Diana Wellesley, Tracy Boyle, John Barber
}

\section{Editorial by \\ Raeburn \\ Wessex Maternal and Fetal Medicine Unit, Princess Anne Hospital, Southampton SO16 5YA \\ David T Howe consultant in fetomaternal medicine Robert Gornall specialist registrar in obstetrics and gynaecology continued over}

BMJ 2000;320:606-10

\author{
Abstract \\ Objective To assess the effectiveness of antenatal \\ screening for Down's syndrome by maternal age and \\ routine mid-pregnancy ultrasound scanning. \\ Design Retrospective six year survey. \\ Setting Maternity units of a district general hospital. \\ Subjects Pregnant women booked for delivery in \\ hospital between 1 January 1993 and 31 December \\ 1998. \\ Main outcome measures All cases of Down's \\ syndrome occurring in district identified from \\ regional congenital anomaly register and cytogenetic \\ laboratory records. Women's case notes were \\ examined to identify indication for karyotyping, \\ gestation at diagnosis, and outcome of pregnancy. \\ Results 31259 deliveries occurred during study \\ period, and 57 cases of Down's syndrome were
}

identified, four in failed pregnancies and 53 in ongoing pregnancies or in neonates. The analysis was confined to ongoing pregnancies or liveborn children. Invasive antenatal tests were performed in $6.6 \%$ (2053/31 259), and 68\% (95\% confidence interval $56 \%$ to $80 \%$ ) of cases of Down's syndrome were detected antenatally, giving a positive predictive value of $1.8 \%$. There were 17 undetected cases, and in seven of these the women had declined an offer of invasive testing. In women aged less than 35 years the detection rate was $53 \%(30 \%$ to $76 \%)$. Most of the cases detected in younger women followed identification of ultrasound anomalies.

Conclusions The overall detection rate was considerably higher than assumed in demonstration projects for serum screening. As a result, the benefits of serum screening are much less than supposed. Before any new methods to identify Down's syndrome 
are introduced, such as nuchal translucency or first trimester serum screening, the techniques should be tested in properly controlled trials.

\section{Introduction}

Down's syndrome is one of the commonest causes of congenital mental handicap, and many parents consider it desirable to diagnose the condition antenatally to allow them the option of terminating an affected pregnancy. The first indicator used to identify pregnancies at high risk was maternal age, but more recently biochemical markers have been used. In 1992, on the basis of their demonstration project of serum screening, Wald et al concluded that its advantages were so great that "the NHS should ensure that antenatal maternal serum screening for Down's syndrome is available throughout Britain." The method gained rapid acceptance, and by 1994 over half of obstetricians in England and Wales were offering it to all women under their care. ${ }^{2}$

The introduction of serum screening was supported by a 1993 report by the Royal College of Obstetricians and Gynaecologists, which considered the evidence for its use. ${ }^{3}$ Four advantages were suggested compared with reliance solely on maternal age:

- It could detect twice as many affected pregnancies for the same rate of amniocentesis

- It could identify affected pregnancies in women below the age cut off

- It could reassure older women whose risk was lower than that predicted by age alone so they might avoid the need for amniocentesis

- At detection rates above $40 \%$, it was more cost effective.

This report derived its evidence from four demonstration projects. ${ }^{14-6}$ Since then, many similar demonstration projects have been published in a wide variety of populations. ${ }^{7-23}$ Despite the large number of studies, we have not been able to identify a single one in which there was a contemporaneous control group of women screened by maternal age. The studies all make a similar assumption about the effectiveness of screening by maternal age-that the maximum success rate of this method will inevitably be limited to the proportion of babies with Down's syndrome born to women above the chosen age cut off. This is variously given as between $20 \%$ and $30 \%$. In this paper we present data suggesting that these assumptions are not borne out in current practice-hence the advantages of serum screening are less than supposed-and we examine the factors that improve the effectiveness of screening by maternal age.

\section{Subjects and methods}

\section{Screening procedures}

At the Princess Anne Hospital, Southampton, screening for Down's syndrome is based principally on maternal age: amniocentesis is offered routinely to women who will be $\geqslant 35$ years old at their estimated date of delivery. All women are also offered an ultrasound scan for anomalies at 19 weeks' gestation, and invasive testing is offered in selected cases where structural anomalies are seen that suggest the fetus is aneuploid. In these cases the amniocentesis would normally be performed within a day or two of a problem being identified. Some women also have ultrasound scans earlier in pregnancy if there is a clinical indication, such as uncertain dates or vaginal bleeding. Serum screening is not offered, but a small number of women organise this privately.

\section{Identification of subjects}

From the records of the Wessex Regional Genetics Laboratory and from the Wessex Antenatally Detected Anomalies Register, we identified all cases of Down's syndrome detected prenatally or postnatally in women booked for delivery in this hospital during the six years from 1 January 1993 to 31 December 1998 inclusive. As a regional centre, the hospital receives referrals from other units for antenatal diagnosis, but we excluded all cases diagnosed in women living outside the health district. We considered that an affected fetus had been successfully detected if the diagnosis was made before 24 weeks' gestation, at a stage in pregnancy when termination can be offered more easily. We examined the notes of all the affected women to identify their address, the indication for karyotyping, the gestation at diagnosis, and the outcome of the pregnancy. Where possible, we confirmed the prenatal diagnosis by checking the results of chromosome analysis performed after delivery.

We estimated the proportion of pregnancies in which an invasive procedure was performed from the total number of births and the number of antenatal karyotype investigations performed in each year during the study period. The hospital does not have a computerised maternity information system, so the age structure of the population during the whole study period could not be determined. Instead, we estimated it by obtaining the date of birth and estimated date of delivery from laboratory records of women who had $\alpha$ fetoprotein screening for spina bifida. These were available for a two year period from 1995 to 1997.

\section{Results}

In the six years studied 31259 babies were delivered in the Princess Anne Hospital or associated community units, and 53 cases of Down's syndrome were detected either during pregnancy or in newborn babies. The overall incidence was 1.7 per 1000 births, consistent with national figures. ${ }^{324}$ One of the affected children, born to a woman aged 29, had a de novo unbalanced Robertsonian translocation (chromosomes 14 and 21), and the remainder were due to non-disjunction. Down's syndrome was identified in a further four failed pregnancies in which the fetal karyotypes had been checked. Three of these women were found to have had missed abortions (failure to expel a fetus after its intrauterine death) at 13, 15, and 16 weeks' gestation, and the other had had a spontaneous miscarriage at 15 weeks in a pregnancy conceived with an intrauterine contraceptive device in situ. These four cases have not been included in the analysis below since they could not have resulted in a liveborn affected child.

Table 1 shows the number of babies born each year and the number of invasive procedures performed. From the records available in the regional laboratory, it is not possible to differentiate in all years between inva-
Wessex Clinical Genetics Service, Princess Anne Hospital,

Southampton

Diana Wellesley

associate specialist in clinical genetics

Wessex Regional

Genetics

Laboratory,

Salisbury District

Hospital, Salisbury

SP2 8BJ

Tracy Boyle

section head, prenatal

diagnostics

John Barber

deputy director,

cytogenetics laboratory

Correspondence to:

D Howe

dth@soton.ac.uk 
Table 1 Numbers of deliveries and pregnancies tested by invasive procedures in Southampton during 1993-8

\begin{tabular}{lcc} 
Year & No of deliveries & $\begin{array}{c}\text { No (\%) of pregnancies tested by } \\
\text { karyotyping }\end{array}$ \\
\hline 1993 & 5547 & $339(6.1)$ \\
\hline 1994 & 5361 & $369(6.9)$ \\
\hline 1995 & 5198 & $335(6.4)$ \\
\hline 1996 & 5030 & $316(6.3)$ \\
\hline 1997 & 5098 & $318(6.2)$ \\
\hline 1998 & 5025 & $376(7.5)$ \\
\hline Total & 31259 & $2053(6.6)$ \\
\hline
\end{tabular}

Table 2 Age distribution of pregnant women in Southampton during 1996-8

\begin{tabular}{lc} 
Age (years) & No $(\%)$ of women \\
\hline$<20$ & $561(7)$ \\
\hline $20-24$ & $1508(20)$ \\
\hline $25-29$ & $2648(34)$ \\
\hline $30-34$ & $2172(28)$ \\
\hline $35-39$ & $703(9)$ \\
\hline $40-44$ & $102(1)$ \\
\hline$\geqslant 45$ & $3(<1)$ \\
\hline Total & 7697 \\
\hline
\end{tabular}

sive procedures carried out on local women and those carried out on women referred from outside the district, since only the hospital where amniocentesis was performed is recorded. Thus, for consistency, we show the total number of procedures performed throughout. This overestimates the procedure rate for our local population, making it $6.6 \%$ (2053/31 259). Since 1996, all invasive procedures performed in Southampton have been recorded on a local database, so we can accurately exclude women referred from elsewhere during 1996-8. In these three years 791 karyotyping procedures were performed and 15153 babies were delivered, giving an invasive procedure rate for local women of $5.3 \%$. This is an appropriate rate when the age structure of the local population is considered (table 2): the mean age was 28.4 years, and $10 \%$ of women were aged $\geqslant 35$.

\section{Antenatal detection of Down's syndrome}

Table 3 shows the number of cases of Down's syndrome diagnosed in each year. The number of cases varied considerably from year to year, and this was accompanied by some fluctuation in the rate of antenatal detection, from $54 \%$ at its lowest to $87.5 \%$ at best. The overall detection rate during the five years was $68 \%(95 \%$ confidence interval $56 \%$ to $80 \%)$. This gives a positive predictive value where women accepted an amniocentesis of $1.8 \%$. An alternative method of viewing this is that 1 in 57 amniocenteses resulted in a diagnosis of Down's syndrome.

Detection in women aged $\geqslant 35$-Table 4 shows the detection rate in older women and the indications for performing amniocentesis. Invasive testing would be offered to all older women routinely, but in three women fetal anomalies were noted on scans carried out before 16 weeks, when amniocentesis would usually be performed. These early scans were performed because of uncertain dates in two women and in the third because she had developed abdominal pain three weeks after insertion of a Shirodkar suture. In each of these three cases the fetus was noted to have a cystic hygroma, accompanied by an abnormal heart in one and by generalised oedema in another.

Detection in women aged $<35$-In younger women the detection rate was $53 \%$ (95\% confidence interval $30 \%$ to $76 \%$ ), and six of the nine cases detected were found after abnormalities were seen on ultrasound scans (table 4). In four of these six cases the scans were routine mid-pregnancy examinations performed at 18-20 weeks, with nuchal pads or cystic hygromas apparent in three and ascites noted in the fourth fetus. The other two cases were detected on earlier scans: one mother had a history of recurrent miscarriage and so was scanned in the first trimester, revealing generalised fetal oedema at 11 weeks' gestation, and in the second case the fetus was noted to have a cystic hygroma on a scan performed at 13 weeks because of uncertain dates. Among the other cases detected in younger women, one was found when a 34 year old woman organised private serum screening, and another was found when a 32 year old woman arranged a private nuchal translucency measurement. If we assume that these two cases would not have been detected for other reasons, the detection rate in younger women would have been $41 \%(17 \%$ to $65 \%)$.

Undiagnosed cases-In total, 17 cases of Down's syndrome were not diagnosed antenatally, eight in women aged $<35$ and nine in older women. Seven of these mothers, six aged $\geqslant 35$ and one younger woman whose fetus was noted to have bilateral pyelectasis and polyhydramnios, had been offered invasive testing but had declined. One of these mothers had privately arranged for nuchal translucency scanning and had received a reassuring result: when the mid-pregnancy anomaly scan suggested the fetal femur was short and the woman was offered amniocentesis for a second time, she again declined. We cannot tell retrospectively whether these mothers declined amniocentesis for fear of miscarriage or for ethical reasons, because they would not have considered termination of pregnancy and would never have accepted an antenatal test. Three of the undiagnosed cases of Down's syndrome occurred in twin pregnancies with a single affected fetus, where serum screening is ineffective: one occurred in a woman aged 33, the second in a woman who required clomiphene to conceive and was just aged 35 at delivery but not offered amniocentesis, and the third in a 41 year old woman who was offered amniocentesis but declined.

In those women in whom Down's syndrome was detected antenatally the mean gestation at diagnosis was 17 completed weeks (range 11-20). We routinely perform amniocenteses for women aged $\geq 35$ at 16 weeks' gestation, and the Wessex Regional Genetics Laboratory reports on these samples in an average of seven days, with the great majority reported within 10 days. The gestation at diagnosis was considered to be the time when the information on which the decision about continuation of the pregnancy was based became available. This was usually when the karyotype result was known, but in two cases the mothers decided on termination on the basis of scan anomalies without waiting for the chromosome analysis.

\section{Discussion}

In the studies of serum screening it has been assumed, but not shown, that the detection rate for Down's syndrome using screening based on maternal age 
would be no higher than $30 \%$. In our population we have shown a much higher detection rate, which results from two factors. The first is the routine use of ultrasound scanning to identify anomalies. This is performed in most units in Britain and was largely responsible for the detection of affected fetuses in women aged less than 35 years. The second is the age structure of the local population, which may have an important influence on the effectiveness of screening by both age and biochemistry. The risk of having an affected pregnancy increases steeply as the mother's age rises above 35 years, so a small increase in the proportion of women over this age produces a disproportionate increase in the percentage of affected pregnancies that occur in the older age group. This was illustrated by a study examining the effects of changing age demographics of women in the United States on the incidence of Down's syndrome. ${ }^{25}$ In 1960 , when almost $11 \%$ of births were to women aged over 35 years, $44 \%$ of affected pregnancies occurred in this age group, but by 1978 the proportion of older women fell to only $4.5 \%$, and only $21 \%$ of cases of Down's syndrome were born to them. In our study $10 \%$ of the women were more than 35 years old, and $66 \%$ of the cases of Down's syndrome occurred in this group, and this contributed to the high detection rate. Serum screening may provide more benefit in populations with a younger age structure, but this needs to be demonstrated in practice since its effectiveness is also reduced in younger women.

\section{Implications for serum screening}

Our findings suggest that the advantages of serum screening are much less in current practice than were suggested in the demonstration projects ${ }^{14-6}$ used in the report by the Royal College of Obstetricians and Gynaecologists. ${ }^{3}$ Firstly, our detection rate using maternal age and ultrasound scanning is within the range shown by demonstration projects of serum screening. A similar study of the detection of Down's syndrome by maternal age and ultrasonography carried out in Isère county in France showed a detection rate for Down's syndrome of 51\%: amniocentesis was offered routinely to women aged over 38 , with $46 \%$ of those cases found antenatally being detected as a result of ultrasound anomalies. ${ }^{26}$ The proportion detected by ultrasonography increased during the study period between 1990 and 1995 from $17 \%$ to $58 \%{ }^{26}$

Secondly, the advantage of biochemical screening at detecting Down's syndrome in women under the age of 35 was also lower than supposed. In our population the detection rate in younger women was $53 \%$ (or $41 \%$ if the cases detected as a result of privately arranged serum or nuchal translucency screening are excluded) with most cases found as a result of ultrasound anomalies. The detection rate was lower than in older women, but this is also true for biochemical screening: in women younger than 35 the detection rate by serum screening ranged between $50 \%{ }^{6}$ and $57 \%{ }^{12}$ compared with $100 \%$ in older women, ${ }^{6}$ while the relative detection rates were $39 \%$ and $71 \%$ in those below or above 37 years old. ${ }^{1}$

A third proposed advantage of serum screening, that it may allow women over the age of 35 to avoid unnecessary invasive testing, may also be overstated. Our findings and those of others ${ }^{27}$ suggest that a normal mid-trimester ultrasound scan reduces the prior risk by a third to a half, and this provides an alter-
Table 3 Number of cases of Down's syndrome detected in ongoing pregnancies or in newborn infants in Southampton during 1993-8

\begin{tabular}{cccc} 
& \multicolumn{3}{c}{ No (\%) of cases } \\
\cline { 2 - 4 } Year & Diagnosed antenatally & Diagnosed postnatally & Total \\
\hline 1993 & $2(67)$ & $1(33)$ & 3 \\
\hline 1994 & $7(54)$ & $6(46)$ & 13 \\
\hline 1995 & $7(64)$ & $4(36)$ & 11 \\
\hline 1996 & $7(88)$ & $1(13)$ & 8 \\
\hline 1997 & $5(83)$ & $1(17)$ & 6 \\
\hline 1998 & $8(67)$ & $4(33)$ & 12 \\
\hline Total & $36(68)$ & $17(32)$ & 53 \\
\hline
\end{tabular}

Table 4 Detection rate of Down's syndrome and indication for invasive testing in women above and below the age of 35 in Southampton during 1993-8

\begin{tabular}{lccc} 
Diagnosis and indication for & \multicolumn{3}{c}{ No (\%) of cases } \\
\cline { 2 - 4 } testing & $\begin{array}{c}\text { Women aged }<\mathbf{3 5} \\
\text { years }(\mathbf{n}=\mathbf{1 7})\end{array}$ & $\begin{array}{c}\text { Women aged } \geqslant \mathbf{3 5} \\
\text { years }(\mathbf{n}=\mathbf{3 6})\end{array}$ & All women $(\mathbf{n}=\mathbf{5 3})$ \\
\hline Not diagnosed & $8(47)$ & $9(25)$ & $17(32)$ \\
\hline Diagnosed: & $9(53)$ & $27(75)$ & $36(68)$ \\
\hline Ultrasound anomaly & $6(35)$ & $3(8)$ & $9(17)$ \\
\hline Previous history & $1(6)$ & $2(6)$ & $3(6)$ \\
\hline Nuchal translucency & $1(6)$ & 0 & $1(2)$ \\
\hline Serum screening anomaly & $1(6)$ & 0 & $1(2)$ \\
\hline Maternal age & 0 & $22(61)$ & $22(42)$ \\
\hline
\end{tabular}

native mechanism to offer reassurance. We are not aware of any studies that have investigated whether ultrasonography or biochemical screening is more effective at such risk adjustment.

The economic arguments for serum screening are valid only if it provides a large increase in the detection rate of Down's syndrome. The Royal College of Obstetricians and Gynaecologists' report suggested that it would be cost effective at detection rates above $40 \%$. The costs of serum screening were examined by Sheldon and Simpson in $1991 .^{28}$ They assumed that $80 \%$ of women would accept screening and that $75 \%$ of those with a positive result would accept amniocentesis, but their calculations did not allow for any additional time spent counselling women about the test. ${ }^{29}$ They calculated that, at prevailing prices, the average cost of avoiding each birth of an infant with Down's syndrome was $£ 29341$, whereas the excess cost for caring for an affected child was $£ 90000$. However, if the improvement in the detection of Down's syndrome is small, the marginal cost for each additional affected fetus identified is considerably higher than the average cost per case, ${ }^{30}$ and the economic arguments for biochemical screening are invalidated.

The demonstration projects of serum screening have made little mention of the potential disadvantages. One of the greatest problems is with counselling before the test. Health professionals involved in advising women may have limited understanding of the test themselves ${ }^{31}$ or feel that they have inadequate facilities to offer full information. ${ }^{2}$ Thus, despite clearly defined standards about counselling for serum screening, ${ }^{3}$ many women do not understand the test properly before undergoing it: in one study, even after counselling, only $38 \%$ of women were aware that the test screened for Down's syndrome, only 32\% were aware that most women with a positive result would have a normal child, and only $36 \%$ understood that a negative result did not completely exclude aneuploidy. ${ }^{32}$ Furthermore, some women whose screening tests were 


\section{Key messages}

- Serum screening for Down's syndrome has never been compared with screening by maternal age in a controlled trial

- This study examined the effectiveness of screening by maternal age in combination with mid-trimester ultrasound scanning

- The overall detection rate was $68 \%$, considerably more effective than assumed in demonstration projects of serum screening

- The benefits of serum screening, compared with screening by maternal age in conjunction with routine fetal anomaly scanning, may be much less than supposed

- A higher standard of evidence should be demanded before proposed new screening methods are adopted

positive felt that their local units were unprepared for dealing with such results. ${ }^{33}$

\section{Conclusions}

Our data challenge the assumptions about screening for Down's syndrome based on maternal age that underpinned the introduction of second trimester serum screening. We cannot discount the possibility that the addition of serum screening in our population would raise our detection rate further, but this could only be tested by a properly controlled trial, and the Wessex Antenatally Detected Anomalies Register shows no evidence of higher detection rates of Down's syndrome in districts in Wessex that use serum screening compared with those that do not. ${ }^{34}$ The need for such a trial was pointed out as long ago as $1991,{ }^{28}$ but serum screening is now so firmly established in clinical practice that it is unlikely that it will ever be tested properly. We urge that before other new screening methods are introduced-such as first trimester, ${ }^{35}$ improved second trimester serum screening, or nuchal translucency measurement ${ }^{36}$-clear evidence be obtained of their effectiveness compared with current practice in properly conducted controlled trials that state the age structure of the populations studied.

Contributors: The paper was conceived and produced as a collaboration between the departments of fetal medicine and clinical genetics in Southampton and cytogenetics in Salisbury. Data for analysis was taken from the regional congenital anomaly database maintained by DW and from laboratory records obtained by $\mathrm{JB}$ and $\mathrm{TB}$, who also performed the cytogenetic analyses. DTH and RG performed most of the analyses of clinical data. All authors contributed to the final version of the paper. DTH is guarantor for the paper.

Funding: None.

Competing interests: None declared.

1 Wald NJ, Kennard A, Densem JW, Cuckle HS, Chard T, Butler L. Antenatal maternal serum screening for Down's syndrome: results of a demonstration project. BMJ 1992;305:391-4.

2 Green JM. Serum screening for Down's syndrome: experiences of obstetricians in England and Wales. BMJ 1994:309:769-72.

3 Royal College of Obstetricians and Gynaecologists. Report of the working party on biochemical markers and the detection of Down's syndrome. London: RCOG Press, 1993.

4 Haddow JE, Palomaki GE, Knight GJ, Williams J, Pulkkinen A, Canick JA, et al. Prenatal screening for Down's syndrome with use of maternal serum markers. N Engl J Med 1992;327:588-93.

5 Cheng E, Luthy D, Zebelman A, Williams M, Lieppman R, Hickok D. A prospective evaluation of a second-trimester screening test for fetal Down syndrome using maternal serum alpha-fetoprotein, hCG, and unconjugated estriol. Obstet Gynecol 1993;81:72-7.

6 Goodburn SF, Yates JRW, Raggatt PR, Carr C, Ferguson-Smith ME, Kershaw AJ, et al. Second trimester maternal serum screening usin alpha-fetoprotein, human chorionic gonadotrophin, and unconjugated oestriol: experience of a regional programme. Prenatal Diagnosis 1994;14:391-402.

7 Burton B, Prins G, Verp M. A prospective trial of prenatal screening for Down syndrome using maternal serum alpha-fetoprotein, hCG and unconjugated estriol. Am J Obstet Gynecol 1993;169:526-30.

8 Mancini G, Perona M, Dall'Amico D. Maternal serum markers. Estimation of the risk of Down's syndrome: a prospective study. Int J Clin Lab Res 1994;14:49-53.

9 Mooney R, Peterson J, Franch C, Saller D, Arvan D. Effectiveness of combining maternal serum alphafetoprotein and hCG in a second-trimester screening program for Down syndrome. Obstet Gynecol 1994;84:298-303.

10 Kellner L, Weiss R, Weiner Z. The advantages of using triple-marker screening for chromosomal abnormalities. Am J Obstet Gynaecol 1995;172:831-6.

11 Dawson A, Jones G, Matharu M, Reynolds TM, Penney MD, John R, et al. Serum screening for Down's syndrome. Br J Obstet Gynaecol 1993;100:875-7.

12 Phillips OP, Elias S, Shulman LP, Andersen RN, Morgan CD, Simpson JL Maternal serum screening for fetal Down syndrome in women less than 35 years of age using alpha-fetoprotein, hCG, and unconjugated estriol: a prospective 2-year study. Obstet Gynecol 1992;80:353-8.

13 Pescia G, Dao M, Wekhs D. Le triple depistage del la trisomie 21: resultats prospectifs de 7039 evaluations. Rev Med Suisse Romande 1993;113:277-80.

14 Piggott M, Wilkinson P, Bennett J. Implementation of an antenatal screening programme for Down's syndrome in two districts (Brighton and Eastbourne). J Med Screening 1994;1:45-9.

15 Beekhuis J. Maternal serum screening for fetal Down's syndrome and neural tube defects. A prospective study performed in the north of the Netherlands [PhD thesis]. Gronigen: Gronigen University, 1993.

16 Crossley J, Aitken D, Berry E, Connor J. Impact of a regional screening programme using maternal serum alpha fetoprotein (AFP) and human chorionic gonadotrophin (hCG) on the birth incidence of Down's syndrome in the west of Scotland. J Med Screening 1994:1:180-3.

17 Macri J, Spencer K, Garver K. Maternal serum free beta hCG screening: results of studies including 480 cases of Down's syndrome. Prenatal Diag nosis 1994;14:97-103.

18 Lam YH, Ghosh A, Tang MH, Tang LC, Lee CP, Sin SY, et al Second-trimester maternal serum alpha-fetoprotein and human chorionic gonadotrophin screening for Down's syndrome in Hong Kong. Prenatal Diagnosis 1998;18:585-9.

19 McDuffie RS Jr, Haverkamp AD, Stark CF, Haverkamp C, Barth CK. Prenatal screening using maternal serum alpha-fetoprotein, human chorionic gonadotropin, and unconjugated estriol: two-year experience in a health maintenance organization. J Maternal-Fetal Med 1996;5:70-3

20 Spencer K, Carpenter P. Prospective study of prenatal screening for Down's syndrome with free beta human chorionic gonadtrophin. BMJ 1993;307:764-9

21 Salonen R, Turpeinen U, Kurki L, Lappalainen M, Ammala P, Hiilesmaa $\mathrm{V}$, et al. Maternal serum screening for Down's syndrome on population basis. Acta Obstet Gynecol Scand 1997;76:817-21.

22 Valerio D, Aiello R, Altieri V, Fagnoni P. Maternal serum screening of fetal chromosomal abnormalities by AFP, UE3, hCG and free-beta hCG. Prospective and retrospective results. Minerva Ginecologica 1996;48:169-73.

23 Van Rijn M, Christiaens GC, van der Schouw YT, Hagenaars AM, de Pate JM, Visser GH. [Maternal serum screening for Down syndrome and neural tube defects]. Nederlands Tijdschrift voor Geneeskunde 1998;142(8):40915.

24 Cuckle HS, Nanchahal K, Wald NJ. Birth prevalence of Down's syndrome in England and Wales. Prenatal Diagnosis 1991;11:29-34.

25 Adams M, Erickson J, Layde P, Oakley G. Down's syndrome: recent trend in the United States. JAMA 1981;246:758-60.

26 Cans C, Amblard F, Devillard F, Pison H, Jalbert P, Jouk P. Population screening for aneuploidy using maternal age and ultrasound. Prenatal Diagnosis 1998;18:683-92.

27 Nyberg D, Resta R, Luthy D, Hickok D, Mahong B, Hirsch J. Prenatal sonographic findings of Down syndrome: review of 94 cases. Obstet Gynecol 1990;76:370-8.

28 Sheldon TA, Simpson J. Prenatal screening for Down's syndrome [letter] BMJ 1991;303:55-6.

29 Keatinge RM, Williams ES. Prenatal screening for Down's syndrome [letter]. $B M J$ 1991;303:54-5.

30 Davies T, Kha OS. Prenatal screening for Down's syndrome [letter]. BMJ 1991;303:312

31 Sadler M. Serum screening for Down's syndrome: how much do health professionals know? BrJ Obstet Gynaecol 1997;104:176-9.

32 Smith DK, Shaw RW, Marteau TM. Informed consent to undergo serum screening for Down's syndrome: the gap between policy and practice. BMJ 1994;309:776-7.

33 Statham H, Green J. Serum screening for Down's syndrome: some women's experiences. BMJ 1993;307:174-6.

34 Wellesley D. Annual report from the Wessex antenatally detected anomalies register. Southampton: Wessex Regional Genetics, Princess Anne Hospital, 1999.

35 Wald NJ, George L, Smith D, Densem JW, Petterson K. Serum screening for Down's syndrome between 8 and 14 weeks of pregnancy. Br J Obstet Gynaecol 1996;103:407-12.

36 Pandya PP, Snijders RJM, Johnson SP, Brizot MdL, Nicolaides KH. Screening for fetal trisomies by maternal age and fetal nuchal translucency thickness at 10 to 14 weeks of gestation. Br J Obstet Gynaecol 1995; 102:957-62.

(Accepted 2 December 1999) 